\title{
REVISÃO/REVIEW
}

\section{GOTA: UMA REVISÃO}

\section{GOUT: A REVIEW}

Felipe Dunin dos Santos ${ }^{1}$

\section{RESUMO}

Gota é uma artrite inflamatória que atinge cerca de $4 \%$ da população, em especial homens de meia-idade. Sua fisiopatologia envolve a deposição de cristais de urato e inflamação. Novas descobertas acerca dos mecanismos da inflamação levaram ao desenvolvimento de novas medicações que trazem novas perspectivas para o tratamento da gota. Porém, a aderência continua sendo um dos maiores inconvenientes no tratamento dos pacientes.

Descritores: Gota. Ácido úrico. Revisão.

\section{ABSTRACT}

Gout is an inflammatory arthritis that affects around 4\% of the population, especially middle-aged men. Its physiopathology depends on urate crystals deposition and inflammation. New discoveries about the pathways leading to inflammation have led to the development of new drugs, which bring us new perspectives of gout's treatment. However, patient's adherence still is one of the greatest challenges in treatment.

Keywords: Gout. Uric acid. Review.

Contato do Autor / Mail to:

Felipe Dunin dos Santos - felipedunin@gmail.com

Rua General Carneiro, 181, $11^{\circ}$ andar 


\section{INTRODUÇÃO}

Gota é uma artrite inflamatória causada pela cristalização do ácido úrico, que se deposita no interior da articulação e está associada à hiperuricemia. É considerada uma das mais dolorosas formas de artrite, caracterizada pelo surgimento abrupto de dor articular de grande intensidade. Descrita há mais de dois milênios, somente na última metade do século 20 veio a confirmação de que a patogênese envolveria a deposição de cristais de urato, devido à introdução dos microscópios de luz polarizada na prática clínica, permitindo a identificação dos cristais e da relação entre estes e a gota ${ }^{1}$.

Conhecida como a doença dos reis, pode ter afetado personalidades tais como Alexandre o Grande, Voltaire, Isaac Newton, Voltaire, Charles Darwin e Leonardo da Vinci13 e sempre esteve relacionada aos homens de meia-idade das classes mais abastadas, com uma vida menos regrada e associada ao sedentarismo e aos excessos.

Avanços no entendimento da fisiopatologia da gota permitiram melhora no tratamento e nos forneceram meios de prevenir e reverter os efeitos danosos da inflamação aguda e crônica sobre as articulações decorrentes da deposição de ácido úrico. Todos estes avanços influenciam o curso da gota nos pacientes atingidos. Porém, a aderência dos pacientes ao tratamento ainda é um problema.

\section{EPIDEMIOLOGIA E FATORES DE RISCO}

Os dados epidemiológicos existentes sugerem que a gota é uma doença prevalente que apresenta aumento na sua incidência desde os anos 1970. A prevalência de gota nos EUA foi estimada em 3,9\%, o que se traduziria em cerca de 8,3 milhões de pessoas, estimada entre 2007 e 2008, atingindo na maioria homens (5,9\% desta população), enquanto entre as mulheres foi de 2\%1-3.Em outros países, como Nova Zelândia, Reino Unido e China, a tendência de aumento da prevalência vem se confirmando semelhantemente aos EUA.

Quanto à incidência da gota, o John Hopkins Precursors Study, observou 1216 estudantes por um tempo médio de 29 anos, a estimando em 1,73 por 1000 pessoas-ano. Na coorte de Framingham, que seguiu 5209 pessoas por 28 anos, resultou numa incidência em 1000 pessoas-ano de 1,4 entre mulheres e de 4,0 entre homens ${ }^{4}$.

\section{Fatores de risco}

Nos adultos, a concentração média de ácido úrico sérico em homens é cerca de 1 a $1,5 \mathrm{mg} / \mathrm{dl}$ maior do que em mulheres da mesma idade, por uma maior fração excretora de urato mediada por hormônios estrogênicos no sexo feminino. Isto explica em parte a baixa incidência de gota entre mulheres jovens, e o aumento da sua incidência durante a menopausa, quando os níveis séricos de ácido úrico se aproximam dos masculinos. 0 uso combinado de estrogênio e progesterona pode resultar em uma redução no ácido úrico sérico em mulheres hiperuricêmicas em pós-menopausa 5 . Afro-americanos tem níveis mais elevados de ácido úrico em relação aos caucasianos ${ }^{6}$.

Estilo de vida: Obesidade é um dos maiores riscos para hiperuricemia e gota, ao reduzir a excreção de ácido úrico e aumentando a produção de purinas. Ingesta aumentada de carnes vermelhas, frutos do mar e peixes, parece ter um efeito de aumento da incidência de gota. 0 aumento de ingesta de gorduras saturadas está relacionado com aumento da resistência insulínica, a qual reduz a excreção renal de urato. Pessoas que ingerem grandes quantidades de laticínios, principalmente os de baixo teor de gordura, têm menor risco de gota12.

Ingesta de bebidas alcoólicas está associada com aumento de risco de gota de forma dependente da dose, independentemente do tipo de bebida alcoólica7,8. 0 álcool induz hiperuricemia tanto pelo aumento da produção de uratos quanto pela redução da excreção. Consumo de café reduz o nível de ácido úrico a longo prazo, ao bloquear a ação da xantina-oxidase, além de reduzir os níveis de insulina e aumentar a sensibilidade do organismo à insulina. Alta ingesta de vitamina $\mathrm{C}$ também reduziu o nível sérico de ácido úrico ${ }^{9}$.

Certas medicações podem afetar nos níveis de ácido úrico no organismo. Baixas doses de salicilato, fenofibrato, losartana e bloqueadores de canais de cálcio reduzem os níveis séricos de ácido úrico. Betabloqueadores e tiazídicos aumentam níveis de ácido úrico sérico10. Exposição crônica ao chumbo pode causar gota mesmo em pequena monta ${ }^{11}$.

\section{ETIOLOGIA E PATOGÊNESE}

Urato é o produto final da degradação de purinas no organismo humano e em alguns primatas, pela ausência do gene que decodifica a enzima uricase. Esta enzima produz um composto mais solúvel, conhecido como alantoína. A ausência da uricase, combinada com reabsorção aumentada do urato filtrado resulta em níveis plasmáticos de ácido úrico cerca de 10 vezes maior do que em outros mamíferos. Os maiores níveis de ácido úrico nos seres humanos pode estar relacionado com a função antioxidante deste, por conseguir remover radicais livres tão efetivamente quanto a vitamina $\mathrm{C}$, sendo $\mathrm{O}$ antioxidante mais abundante no corpo humano. 0 ácido úrico pode agir na vigilância imune, atuando como adjuvante endógeno para disparar a resposta imune inata e específica, ao ser liberado por células em processo de morte celular ${ }^{13}$.

Os níveis de urato são influenciados por vários fatores, incluindo temperatura, $\mathrm{pH}$, concentração de cátions, nível de desidratação e outros, que podem alterar o risco de gota relacionado com uma elevação no nível de urato, além de explicar o porquê de ser a primeira 
metatarso-falangeana uma articulação comumente atingida (onde a temperatura é mais baixa). A quantidade de urato depende da ingesta, síntese e taxa de excreção, podendo em $10 \%$ dos casos resultar de superprodução e em $90 \%$ dos casos de uma baixa excreção, ou uma combinação dos dois ${ }^{20}$. A ingesta diária de urato é baixa e pouco absorvida. As purinas são mais abundantes em comidas e bebidas e podem contribuir para a deposição. A grande massa vem da síntese endógena, principalmente no fígado. Em condições normais, o excesso de ácido úrico é balanceado pela excreção renal, cerca de $2 / 3$ do total. $A$ secreção pelo intestino delgado e sua consequente quebra pelas bactérias do intestino corresponde ao $1 / 3$ restante 20 .

A ingesta de purinas contribui substancialmente para os níveis séricos de ácido úrico. Sua adição à dieta revelou um aumento variável nos níveis de ácido úrico, sendo maior entre ribonucleotídeos, e na adenina em relação à guanina (figura 1$)^{12}$.

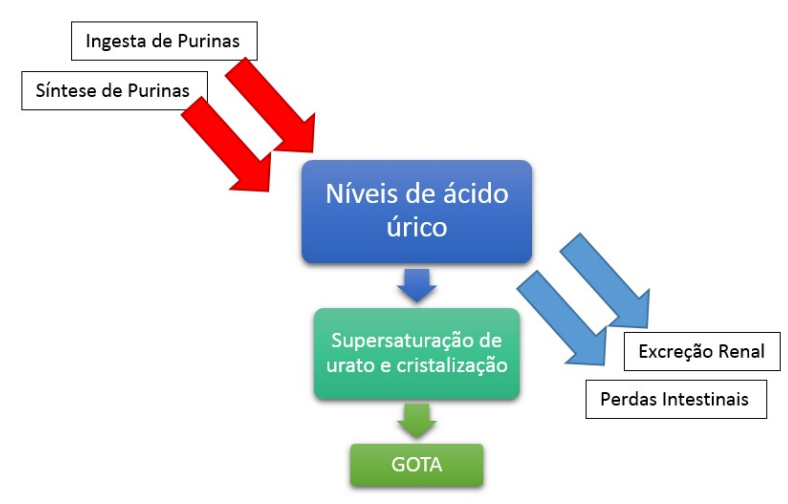

Figura 1. Balanço dos níveis séricos de ácido úrico

\section{Metabolismo de purinas e gota}

A produção endógena de purinas ocorre por síntese de novo, envolve o ciclo das pentoses-fosfato, e sua degradação culmina nos precursores de urato (figura 2). A maioria dos nucleotídeos são reutilizados por meio da enzima hipoxantina-guanina fosforibosiltransferase. 0 restante da guanina perde grupamentos amino e se transforma em xantina. A hipoxantina não utilizada é transformada em xantina, e sofre mais oxidação até o urato. A enzima xantina oxidase catalisa a reação de redução da xantina e hipoxantina em urato, e pode ter sua ação modificada de acordo com os medicamentos e alimentos acima assinalados 12 .

\section{Excreção renal do ácido úrico}

Composto de quatro componentes: filtração, reabsorção, secreção e reabsorção pós-secretória. No túbulo proximal, temos o transportador URAT1 (Urate transporter 1), altamente específico para ácido úrico, mediando sua reabsorção dos rins para a circulação. As drogas uricosúricas aumentam a excreção renal do ácido úrico ao bloquear o URAT1, que ainda tem afinidade por compostos orgânicos aromáticos, como o nicotinato, lactato, nitrato e cloreto.

O transportador GLUT9 (glucose transporter 9) é, assim como o URAT1, um dos membros da família dos transportadores de ácidos orgânicos (OATs), sendo um transportador mediado por voltagem que regula a reabsorção da célula tubular para a circulação. Expresso também na membrana basocelular de hepatócitos, regula as concentrações do ácido úrico por meio destas duas locações.

Outros transportadores podem auxiliar na excreção renal, como o ABCG2, os NPT1 e 4, e outros OAT13.

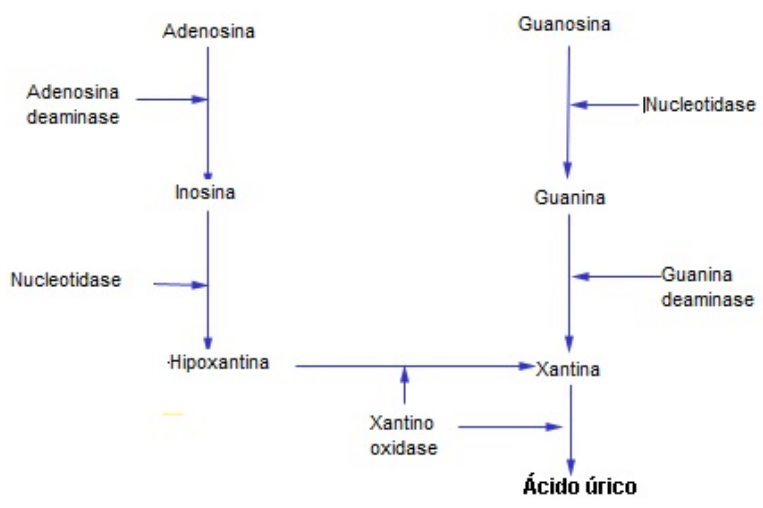

Figura 2. Catabolismo das purinas

\section{Inflamação induzida pelos cristais de urato}

A formação dos cristais de urato monossódico necessita da supersaturação do urato, e dos fatores relatados nos tópicos acima. Lesões articulares prévias podem facilitar a formação de cristais. Mesmo pessoas sem gota clínica podem ter uma concentração de cristais de urato nas articulações ${ }^{13}$.

$\mathrm{Na}$ crise aguda de gota, os cristais iniciam uma atividade inflamatória dependendo de múltiplos fatores, como o tamanho dos cristais, as proteínas que os envolvem e as células que os encontram primeiro. Apesar do potencial de liberação de toda esta cascata inflamatória, eles não ativam necessariamente a inflamação, como visto em pacientes com gota tofácea crônica. Caso haja a deposição ou a liberação dos cristais de depósitos pré-formados, há uma infiltração por neutrófilos, monócitos e macrófagos. A interação com os fagócitos ocorre por dois meios: primeiro, ativam as células por meio da via convencional, forma estereotípica de fusão lipossomal e liberação de mediadores inflamatórios (e que gera a imagem típica da fagocitose de cristais que é critério diagnóstico da doença). 0 outro mecanismo envolve propriedades particulares do cristal de se envolver com as membranas celulares por perturbação e ligação cruzada das glicoproteínas de membrana no fagócito, ativando proteínas G, fosfolipase C e D, SYK quinases, quinases ERK1/ERK2, cinases c-Jun N-terminal e outras, o 
que leva à expressão de IL-8 induzida por cristais. Outras interleucinas, como a IL-1, a IL-6 e o TNF-alfa estão associados com a inflamação. Há ainda a ativação do sistema complemento, aumento da permeabilidade vascular e outras prostaglandinas vasoativas ${ }^{13}$.

A interação dos neutrófilos endoteliais leva a um maior fluxo de neutrófilos e maior ativação da cascata inflamatória.

A IL-1 age na iniciação e na amplificação do ataque de gota por meio do inflamossomo, um complexo de proteínas celulares que é ativado quando há a exposição a elementos microbianos como o RNA bacteriano e toxinas. A ativação deste complexo leva à

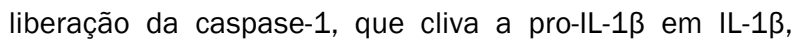
agindo de forma essencial na fisiopatologia da inflamação da gota15. Quase sempre, a crise de gota é autolimitada, resolvendo em uma a duas semanas. A limpeza dos cristais pelos macrófagos leva à inibição dos leucócitos e ativação endotelial. Isto, somado ao aumento da permeabilidade vascular e à liberação de estímulos antiinflamatórios como 0 aumento de corticosteroides endógenos e interleucinas anti-inflamatórias leva à resolução do ataque de gota. Simultaneamente, há a liberação de enzimas proteolíticas para quimiocinas, lipoxinas e outras que ajudam na resolução de flares agudos.

\section{Gota Crônica}

Pacientes com gota há muitos anos apresentam mediadores inflamatórios envolvidos na inflamação aguda e da inflamação crônica, o que leva à sinovite, erosão óssea e sinovite crônica. Os tofos se formam devido aos agregados de cristais envelopados por uma resposta semelhante a granuloma, com uma zona de células gigantes circundadas por uma camada fibrosa. As erosões se localizam em torno de tofos, e são radiograficamente distintas das lesões erosivas presentes na artrite reumatoide. Cristais de urato levam a efeitos nos osteoblastos e causam viabilidade celular reduzida nestes tipos celulares, justificando a reabsorção óssea nos sítios de localização dos tofos. Dano cartilaginoso é uma manifestação mais tardia da gota, e estudos ultrassonográficos mostram a relação entre os cristais e a cartilagem articular, tendo o sinal do duplo-contorno sido visualizado sobre a margem superficial da cartilagem articular, podendo representar o acúmulo dos cristais nestas locações ${ }^{13}$.

\section{CLÍNICA}

A história natural da gota é de progressão de um período prolongado assintomático de acúmulo de cristais de urato monossódico nas articulações, intercalado com fases de mono ou oligoartrite para uma fase de artrite crônica com a presença de depósitos de cristais conhecidos como tofos.

\section{Hiperuricemia assintomática}

Termo associado com a elevação da concentração de urato sérico, na ausência de sintomas, sendo uma alteração bioquímica relativamente comum, principalmente nos últimos 20 anos. As manifestações podem vir a se desenvolver em cerca de um terço dos pacientes. A hiperuricemia está relacionada com outras afecções não relacionadas com a deposição de cristais, como hipertensão, insuficiência renal, doença cardiovascular, resistência insulínica, obesidade e diabetes.

A definição de hiperuricemia não é bem clara, mas uma concentração acima de $6,8 \mathrm{mg} / \mathrm{dl}$ corresponde ao ponto de saturação do urato nos fluidos biológicos, quando medidos por métodos enzimáticos ${ }^{13}$.

Há associação entre a hiperuricemia e a doença renal crônica, devido à redução da eficiência de excreção de urato. Nas doenças com alto turnover celular, há alta produção de ácido úrico. Transplantes também estão bastante associados com o aumento do nível sérico de ácido úrico, devido ao uso de inibidores de calcineurina (ex: ciclosporina).

\section{Gota Intermitente aguda}

Ocorre por volta da quarta década em homens, e mais tarde nas mulheres, dependendo da idade da menopausa. Os ataques apresentam dor importante, edema e dificuldade de mobilização, com pico de inflamação ocorrendo dentro das primeiras 24 horas, e dificuldades inclusive de manter toques extremamente suaves sobre a articulação atingida, como o toque do lençol da cama. Os ataques resolvem-se dentro de poucos dias, seguidos de descamação da pele sobre a articulação afetada. Ocorrem normalmente à noite e no início da manhã, são monoarticulares, podendo apresentar sinais de inflamação se estendendo além da articulação primariamente atingida, dando a impressão de dactilite ou celulite ${ }^{14}$. Envolvimento de tornozelo, punhos, quirodáctilos ou bursa olecraniana pode ocorrer inicialmente, mas é mais raro ${ }^{15}$. Em mais de $90 \%$ dos casos, a primeira metatarsofalangeana é articulação mais atingida, sendo a artrite que acomete esta articulação denominada podagra (figura 3). As articulações referidas acima normalmente são atingidas nos episódios subsequentes.

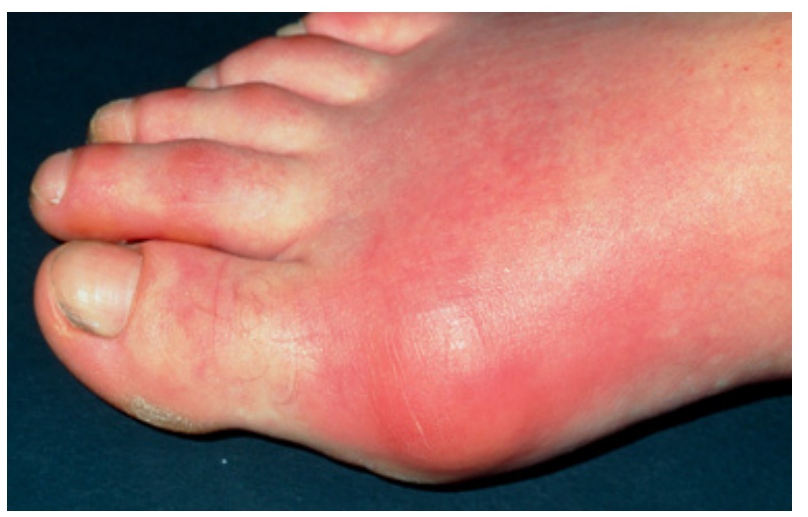

Figura 3. Podagra 
0 ataque agudo pode ser ativado por qualquer fator que altere a estabilidade dos cristais no interior da articulação, como alteração do $\mathrm{pH}$ do líquido sinovial, trauma articular ou quaisquer motivos que alterem a cristalização dos cristais. Exposição a purinas e a álcool, em especial cerveja pode estar relacionado com a crise, bem como a redução dos níveis séricos de urato.

\section{Gota aguda poliarticular}

Manifestação inicial em menos de $20 \%$ dos pacientes com gota, porém mais frequente nos quadros subsequentes. É mais comum em pacientes com doenças mieloproliferativas ou usuários de inibidores da calcineurina. Pode ser migratória ou simultânea, envolvendo articulações e bursas.

\section{Gota intercrítica}

Intervalo assintomático após a resolução de ataques agudos da gota e tão infrequente em outras causas de artrite que é extremamente sugestivo do diagnóstico. Os intervalos são variáveis, sendo em média de dois anos após a primeira crise. Os pacientes quando não tratados tendem a ter ataques com menor período intercrítico. A deposição de material tofáceo pode ocorrer, com artropatia gotosa crônica, erosões e lesões articulares.

\section{Gota tofácea crônica}

Caracterizada por coleções de ácido úrico com alterações destrutivas no tecido circundante (figura 4). Os tofos são visíveis, palpáveis e indolores, podem estar presentes em superfícies digitais e nas orelhas, com coloração amarelada quando superficialmente sob a pele. Pode se estender além das articulações, produzindo alterações das partes moles e alterações expansivas, ser confundido com nódulos reumatoides, osteomielite e levar a amputações

Ao exame histopatológico, os tofos apresentam reação granulomatosa. São patognomônicos da doença, e ocorrem mais frequentemente nos dígitos, punhos, orelhas, joelho, olécrano, pontos de pressão na ulna, no tendão de Aquiles, em nódulos de Heberden e em locais como as pirâmides renais, válvulas cardíacas e na esclera, podendo inflamar e infeccionar.

\section{DIAGNÓSTICO}

Critérios classificatórios foram desenvolvidos pelo ACR (American College Of Rheumatology) e pelo EULAR (European League Against Rheumatism) em 2015, de forma a agrupar os pacientes em um grupo semelhante, e permitem que um paciente seja classificado como portador de gota caso tenham sofrido um episódio de dor ou edema em uma articulação ou bursa com a presença de cristais de urato em alguma locação ou sem a positividade do líquido, mas com sinais clínicos ou exames de imagem positivos $^{16}$. A sensibilidade e a especificidade dos critérios são altas, atingindo $92 \%$ e $89 \%$, respectivamente.

O diagnóstico em pacientes com quadro suspeito de gota aguda, mas em quem a causa da artrite ainda é incerta deve ser feito com base em exames laboratoriais, incluindo artrocentese, com contagem celular, Gram e cultura, e exame dos cristais sob luz polarizada. É mais acurado quando cristais de uratos são vistos intracelulares sob microscopia de luz polarizada de uma articulação afetada, demonstrando cristais de birrefringência negativa. A gota pode coexistir com outra doença articular tal como artrite séptica ou pseudogota. Isso reforça a necessidade de avaliação do líquido sinovial.

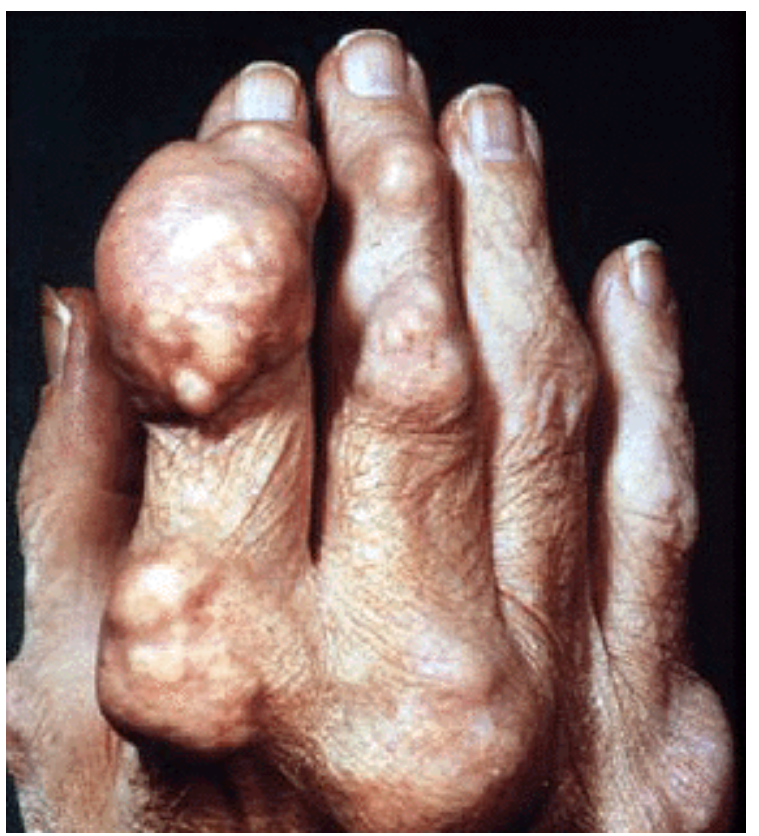

Figura 4. Gota tofácea crônica

O diagnóstico deve ser baseado numa história clínica condizente e elevação dos níveis séricos de urato. Um grande número de crises ocorre em pacientes que apresentam um nível normal ou até mesmo baixo de urato sérico, e existem pacientes com artrite de outras causas e hiperuricemia concomitante. A acurácia do diagnóstico clínico na ausência de cristais é mais baixa.

No caso dos quadros crônicos, os cristais podem ser vistos em articulações previamente afetadas, em cerca de $70 \%$ dos pacientes, mesmo naqueles utilizando terapia hipouricêmica, o que permite o diagnóstico não somente durante as crises agudas. A presença de cristais nos tofos também contribui para o diagnóstico, que pode ainda ser realizado por meio de exames histopatológico das lesões e busca de cristais de urato.

O líquido sinovial de pacientes com gota é caracterizado pela presença de cristais de ácido úrico intra e extracelular visualizados por meio de luz polarizada, apresentando birrefringência negativa, podendo ainda ser aspirados diretamente de tofos. O líquido tende a ser 
inflamatório, com celularidade entre 10.000 e 100.000 células e predominância neutrofílica. Os líquidos de outros locais tais como bursas tendem a ter achados semelhantes.

Os exames laboratoriais podem demonstrar elevação da proteína C-reativa, com velocidade de hemossedimentação alta nos ataques agudos, achados inespecíficos.

Exames de imagem podem apresentar várias alterações: a radiografia tem sido usada para confirmar a gota suspeita, porém as imagens clássicas, como erosões em saca-bocado e margens escleróticas ocorrem mais tardiamente no processo.

O ultrassom de alta frequência pode ser utilizado para avaliar pacientes com sinovites, derrames articulares e erosões (figura 5). Cristais podem ser vistos com aparências variáveis, como o aspecto em duplo-contorno que reflete a deposição do urato na cartilagem hialina e apresenta alta especificidade. A sinovite pode ser heterogênea, mas é predominantemente hiperecóica devido ao depósito de urato. A outra vantagem é a visualização de depósitos tofáceos nas bursas, tendões e partes moles ${ }^{17,18}$.

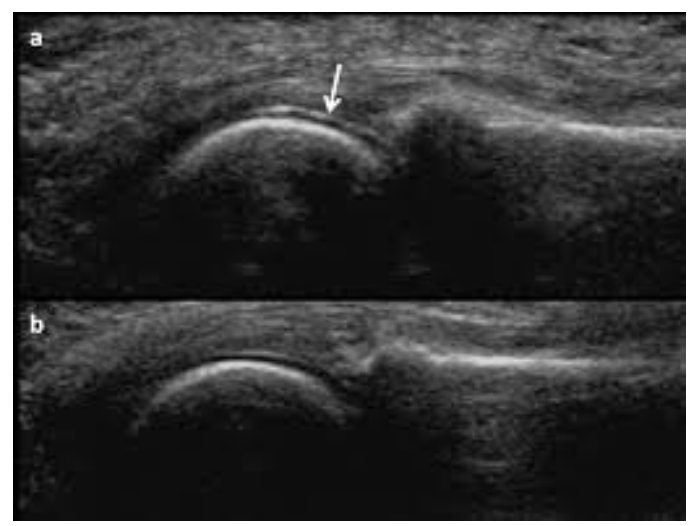

Figura 4. Ultrassom de duas articulações metatarsofalangeanas: (a) sinal do duplo contorno por depósitos de urato na cartilagem; (b) cartilagem de morfologia normal

Para detectar doença precoce, a tomografia computadorizada com dupla energia (DECT) revelou-se útil na identificação da concentração de ácido úrico em diferentes locações, como os rins e as articulações, e comparada com a punção articular, demonstrou boa sensibilidade e especificidade. A medida quantitativa do volume de urato pode ser avaliada, de forma que a redução do urato e o sucesso do tratamento podem ser medidos ${ }^{17,18}$.

\section{TRATAMENTO}

\section{Gota aguda}

O tratamento da gota aguda deve objetivar o alívio rápido da artrite. As drogas mais utilizadas para esta estratégia são os anti-inflamatórios não-esteroidais (AINES), corticoesteroides e a colchicina. O tratamento deve continuar com os anti-inflamatórios até a crise aguda ter se resolvido. Estas medicações estão associadas a alterações gastrointestinais, aumento dos níveis pressóricos e complicações renais.

Corticoesteroides podem ser usados e têm eficácia e tolerância semelhantes aos AINES, necessitando de doses altas para redução do processo inflamatório $(>0,5 \mathrm{mg} / \mathrm{kg})$. Podem ainda ser utilizados de forma intramuscular ou intra-articular, sendo estas com uma ação rápida e efetiva. 0 uso concomitante de colchicina pode reduzir o efeito rebote associado à interrupção do corticoesteroide quando da melhora do quadro ${ }^{13}$.

A colchicina é um alcaloide natural que inibe a fagocitose de cristais de urato monossódico, e as respostas imunes associadas com a imunidade celular. Usada em altas doses em pacientes com gota aguda (ex. 1 $\mathrm{mg}$ seguido de $0,5 \mathrm{mg}$ a cada duas ou três horas, até a melhora), parece ter bom efeito e melhor tolerabilidade que os regimes assinalados acima (doses de $0,5 \mathrm{mg}$ de $12 / 12$ horas) 13 .

\section{Gota intercrítica}

O tratamento a longo prazo tem como objetivo prevenir a formação dos cristais de urato monossódico, impedindo novos ataques de gota e a redução dos tofos. A redução dos níveis de urato é mais facilmente atingida através da união de métodos farmacológicos e nãofarmacológicos.

\section{Tratamento não-farmacológico}

A substituição de diuréticos tiazídicos por outras medicações anti-hipertensivas, redução da ingesta de álcool, em especial a cerveja, perda ponderal e redução da ingesta de alimentos ricos em purina são medidas a serem tomadas.

Deve-se sempre avaliar a aderência dos pacientes ao tratamento e explicar que o tratamento é prolongado e o paciente pode permanecer assintomático pela maior parte do tempo. A educação do paciente sobre a sua doença e sobre a aderência ao tratamento é fundamental.

\section{Tratamento farmacológico}

A droga mais usada é o alopurinol, inibidor nãoespecífico da xantina-oxidase, deve ser iniciado em doses baixas (100 mg/dia) e aumentado em $100 \mathrm{mg}$ a cada mês até a obtenção de níveis séricos desejáveis de ácido úrico. A dose máxima do alopurinol se situa em torno de 800 a $900 \mathrm{mg}$ por dia. Tem como efeitos adversos a possibilidade de desenvolver lesões de pele e a síndrome de hipersensibilidade ao alopurinol, com lesões cutâneas graves e disfunção renal e hepática. A maioria dos pacientes tolera bem o alopurinol, mas podem sofrer uma crise aguda devido às alterações dos cristais de urato nas articulações, fato que pode ser reduzido com doses baixas 
de colchicina associada. Como alternativa, há o febuxostat, que ainda não está disponível no Brasil.

A terapia em pacientes que não toleram ou tem contraindicações ao alopurinol deve ser com base em terapias uricosúricas, tais como a benzobromarona e a probenecida.

Os consensos ainda referem tratar a hiperuricemia em pacientes com alterações clínicas associadas com a gota, não em hiperuricêmicos assintomáticos. Em termos de metas, o objetivo é de manter uma concentração de urato sérico menor que 6 $\mathrm{mg} / \mathrm{dl}$ e menor que $5 \mathrm{mg} / \mathrm{dl}$ naqueles pacientes portadores de tofos, de forma a melhorar a resolução dos tofos. Não se recomenda o uso de medicações redutoras de urato em crises agudas, devendo-se aguardar ao menos duas semanas para iniciar este tratamento, baseando-se no fato de que a redução dos níveis de urato num ataque agudo pode piorar a artrite.

Uricosúricos são medicamentos que podem ser usados em pacientes com baixa excreção renal da ácido úrico, mas não podem ser usados em pacientes com quadros de insuficiência renal ou em pacientes com nefrolitíase. Estas medicações agem inibindo as trocas de urato no túbulo proximal, e têm disponibilidade limitada. Tem como efeitos adversos, o surgimento de rash, precipitação de crise aguda, intolerância gastrointestinal e nefrolitíase 15 .

No Brasil, encontramos disponível apenas a benzobromarona. Apesar de pouco utilizada, apresenta-se bastante efetiva na redução dos níveis de urato sérico naqueles pacientes hipoexcretores.

Novas drogas vêm sendo desenvolvidas nos últimos anos. O Febuxostat é um inibidor potente da xantina-oxidase, e que não é análogo da purina, liberado na Europa e nos Estados Unidos. A pegloticase é uma uricase recombinante de mamíferos e que converte urato para alantoína, disponível nos EUA para tratamento da gota tofácea refratária a um custo bastante elevado. Os inibidores da IL-1 parecem ser um tratamento promissor em pacientes com gota que não toleram agentes tradicionais como corticoesteroides ${ }^{19}$.

O tratamento desta condição é crônico, e uma vez atingido um determinado nível sérico de urato, as medidas devem ser repetidas a cada seis meses para garantir 0 alvo terapêutico. Quando o paciente for considerado livre de cristais, a dose deve ser ajustada para manutenção e mantida a monitorização. A aderência é um ponto importante que deve ser abordado em todas as consultas, assim como a melhora dos hábitos de vida, pois se sabe que a gota está associada a outras alterações sistêmicas que envolvem principalmente o sistema cardiovascular.
2. DOHERTY, M. New insights into the epidemiology of gout. Rheumatology, v. 48, mai. 2009.

3. ROBBY, Edward; DOHERTY, Michael. Epidemiology of gout. Arthritis Research \& Therapy, [S.L], v. 12, n. 223, dez. 2010.

4. RODDY, E.; MALLEN, C. D.; DOHERTY, M. Gout. BMJ, v. 347, n. 5648 , out. 2013.

5. HAK, E.; CHOI, H. K. Menopause, postmenopausal hormone use and serum uric acid levels in US women - The Third National Health and Nutrition Examination Survey. Arthritis Research \& Therapy, v. 10, n. 5, jun. 2008

6. KRISHNAN, E. Gout in African Americans. The American Journal of Medicine, , v. 127, n. 9, p. 858-864, set. 2014.

7. NEOGI, T. et al. Alcohol quantity and type on risk of recurrent gout attacks: an internet-based case-crossover study. American Journal of Medicine, [S.L], v. 127, n. 4, p. 311-318, abr. 2014.

8. CHOI, H. K.; CURHAN, G.; Coffee consumption and risk of incident gout in women: the Nurses' Health Study. American Journal of Clinical Nutrition, v. 92, n. 4, p. 922-927, out. 2010.

9. $\mathrm{CHOI}, \mathrm{H}$. K. et al. Antihypertensive drugs and risk of incident gout among patients with hypertension: population based case-control study.. BMJ, v. 344, n. 8190, jan. 2012

10. KARIS, Elaine; CRITTENDEN, Daria B.; PILLINGER, Michael H.. Hyperuricemia, gout, and related comorbidities: cause and effect on a two-way street. Southern Medical Journal, v. 107, n. 4, p. 235-241, abr. 2014.

11. KRISHNAN, E.; LINGALA, B.; BHALLA, V. Low-Level Lead Exposure and the Prevalence of Gout: An Observational Study. Annals of internal Medicine, v. 157, n. 4, p. 233-241, ago. 2012.

12. PINHEIRO, G. R. C. Revendo a Orientação Dietética na Gota. Revista Brasileira de Reumatologia, v. 48, n. 3, p. 157-161, mai./jun. 2008.

13. HOCHBERG, et al. Rheumatology. 6 ed. [S.L.]: Elsevier, 2015.

14. $\mathrm{CHOI}, \mathrm{H}$. K. et al. Nocturnal risk of gout attacks. Arthritis \& Rheumatology, [S.L], v. 67, n. 2, p. 555-562, fev. 2015.

15. DALBETH, N.; MERRIMAN, T.. Crystal ball gazing: new therapeutic targets for hyperuricaemia and gout. Rheumatology, v. 48, p. 222-226, dez. 2008.

16. NEOGI, T. et al. 2015 Gout Classification Criteria: an American College of Rheumatology/European League Against Rheumatism collaborative initiative. Arthritis \& Rheumatology, v. 67, n. 10, p. 2557-2668, out. 2015.

17. HUANG, M; SCHWEITZER, M. E.. The role of radiology in the evolution of the understanding of articular disease.. Radiology, v. 273, n. 2, p. 1-22, nov. 2014

18. GIRISH, G. ; GLAZEBROOK, K. N.; JACOBSON, J. A.. Advanced Imaging in Gout. American Journal Of Roentgenology, [S.L], v. 201, n. 3, p. 515-525, set. 2013

19. BURNS, C. M; WORTMANN, R. L. Gout therapeutics: new drugs for an old disease. Lancet, v. 377 , n. 9760 , p. 165 177, jan. 2011.

20. CHOI, H. K.; MOUNT, D. B.; REGINATO, A. M.. Pathogenesis of Gout. Annals of Internal Medicine, [S.L], v. 143, p. 499-516, jul.

\section{REFERÊNCIAS}

1. ZHU, Y.; PANDYA, B. J.; CHOI, H. K.. Prevalence of Gout and Hyperuricemia in the US General Population. Arthritis \& Rheumatism, v. 63, n. 10, p. 3136-3141, out. 2011. 